$\S=-1$

\title{
Study of effects of blood alcohol consumption (BAC) level on drivers physiological behavior and driving performance under simulated environment
}

\author{
Murali Subramaniyam ${ }^{1}$ *, Seoung Eun Kim ${ }^{2}$, Seung Nam Min ${ }^{3}$, Heeran Lee ${ }^{4}$, Seung Hee Hong ${ }^{5,6}$, Se Jin Park ${ }^{5,7}$ \\ ${ }^{1}$ Department of Mechanical Engineering, SRM Institute of Science and Technology, Kattankulathur, Chennai, India \\ ${ }^{2}$ Center for Sports Science in Chungnam, Chungnam Sports Council, South Korea \\ ${ }^{3}$ Department of Fire Safety Management, Shinsung University, Dangjin-si, South Korea \\ ${ }^{4}$ Department of Clothing and Textiles, Chungnam National University, Daejeon, South Korea \\ ${ }^{5}$ Center for Medical Metrology, Korea Research Institute of Standards and Science, Daejeon, South Korea \\ ${ }^{6}$ KSB Research Department, Electronics and Telecommunication Research Institute, Daejeon, South Korea \\ ${ }^{7}$ Department of Medical Physics, University of Science and Technology, Daejeon, South Korea \\ *Corresponding author E-mail: sjpark@kriss.re.kr
}

\begin{abstract}
Alcohol consumption impairs driving skills and responsible for a high proportion of traffic accidents. This research examined the effects of blood alcohol consumption (BAC) level on driver's physiological behavior and driving performance under simulated driving environment. The participants consisted of eight healthy young male drivers with an average of eight years driving experience. The scenario considered was 5 min driving on a highway with different speed limits, crossings, and unexpected event. Results showed that statistically significantly decreased alpha and increased theta power frequency was observed with increased BAC level. Heart rate was statistically significantly elevated with increased BAC level. The accident rate and the over speed rate were significantly higher with higher BAC level. Alcohol intoxication affected drivers' decision-making ability, vision and integrating visual information ability.
\end{abstract}

Keywords: Alcohol Intoxication; Cognitive Load; BAC Level; Accident Rate.

\section{Introduction}

Alcohol consumption weakens driving skills and increases the chances of accident risk [1]. Keall et al. [2] said that under the influence of alcohol the danger of having an accident causing injury or death increases. Arnedt et al. [3] noted that the drivers with a slight quantity of alcohol intake are twofold likely to be involved in road traffic accidents than regular drivers. Drunk driving has a significant threat to public safety and health, also imposes a substantial financial loss to the whole society, especially in the healthcare and insurance sector [4]. In Korea, drunken driving is thought to be responsible for 29,293 accidents, 815 deaths, and 52,345 injuries in 2012 [5]. The proportion of drunk driving traffic accidents $(22.7 \%)$, killed $(35.8 \%)$ and injured $(22.7 \%)$ by driver's BAC of $0.05-0.09 \%$. In the USA, drunk driving accidents contribute to about $31 \%$ of all traffic fatal [6]. In China, $34.1 \%$ of road accidents were under drunk driving [7]. The constitutional limits for BAC are varied among countries, for example, $0.05 \%$ in Korea, Australia, $0.08 \%$ in the USA, England, Canada, and $0.02 \%$ in China and Sweden.

Driving under the influence of alcohol can affect driver's thought, watchfulness, attention, decision-making ability, response, depth perception, logical reasoning, visual performance, and visual searches [8-10]. Zhang et al. [11] mentioned that alcohol consumption causes reduced coordination, disorientation, blackouts, reduced self-confidence, and double vision, which causes severe accidents. Chamberlain, E., \& Solomon [12] concluded that driv- er's vision, braking behavior, and vigilance were significantly affected even by the low doses of alcohol consumption. Drunken drive impairs hand steadiness [13], operating accuracy [14], steering behavior [15, 16], braking behavior [12], and driving speed [17].

Human emotion is aroused reactively and instantly by the information received from the external environment; these include temporal and spatial changes [18]. Several driving-related studies used electroencephalogram (EEG) for psychological measures [19], [20]. The EEG spectral parameters would change when mental fatigue is occurring while driving [18], [21-25]. Alcoholism can affect the brain and its neuronal activity, specifically, alpha activity decreases and theta activity increases [11], [26], [27]. Malar et al. [28] claimed that power spectrum could be used to distinguish EEG of alcoholic and control. Also mentioned that decreased alpha activity and increased theta activity can be used to differentiate between alcoholics and control. The electrocardiogram (ECG) used as one of the factors for measuring user attention [23-25], [29], [30]. That is, the influence of alcohol gradually reduce R-R interval variability and increase heart rate [31]. The current study was to examine effects of alcohol (with different $\mathrm{BAC}$ levels) on physiological behavior and driving performance in a simulated driving environment. The physiological measures were EEG (alpha and theta power frequency in the frontal and occipital region), and ECG (heart rate and R-R interval). The driving performance measured were accident rate and the number of time violating the specified speed limit $(50,70,90,110 \mathrm{~km} / \mathrm{h})$. 


\section{Methods}

a) Subjects

There were eight healthy young male participants with valid driver's licenses and had regular driving habits, fixed sleep time, and free from drug use. All the participants have no medical history of cerebral diseases and vision problem to drive a car in the driving simulator. The participant's demographic details including driving experience are presented (Table 1). They agreed and signed informed consent. Statistical power was estimated at G-power 3.0 program with input parameters - effect size (f): 0.5 ; significance level $(\alpha)$ : 0.05 ; sample size: 8 ; the number of groups: 4 . The statistical test considered was (ANOVA: Repeated measures, within factors) and the type of power analysis was: Post hoc: computer achieved power - given $\alpha$, sample size, and effect size. The estimated statistical power $(1-\beta)$ and critical F-value are 0.82 , and 3.49029 , respectively.

Table 1: Subjects Demographic Details

\begin{tabular}{ll} 
& Mean \pm SD \\
\hline N=8 & $29.63 \pm 3.16$ \\
Age, years & $174.53 \pm 7.12$ \\
Weight, $\mathrm{cm}$ & $82.01 \pm 20.33$ \\
BMI, $\mathrm{kg} / \mathrm{m}^{2}$ & $26.80 \pm 5.90$ \\
Driving experience, years & $8.0 \pm 3.4$ \\
\hline
\end{tabular}

b) Experimental Environment and Apparatus

A driving simulator situated in the Chungnam Techno Park at Korea Automobile Technology Institute was utilized (Figure. 1). The simulator was driven under the temperature $\left(25^{\circ} \mathrm{C}\right)$ and relative humidity (40-50\%) controlled environment. Important specification of the simulator is scan rates(horizontal: $\mathrm{kHz}$ to $\mathrm{Hz}$; vertical: 23.97 to $150 \mathrm{~Hz}$ ), resolution (true SXGA+1400 x 1050). The simulator consists of networked computers, steering wheel, pedals, and gear shift. The road scenarios were projected onto big screens with a $130^{\circ}$ field of view. The driving simulator offers various parameters including steering wheel angle, gear state, travelling speed, lane position, and acceleration.

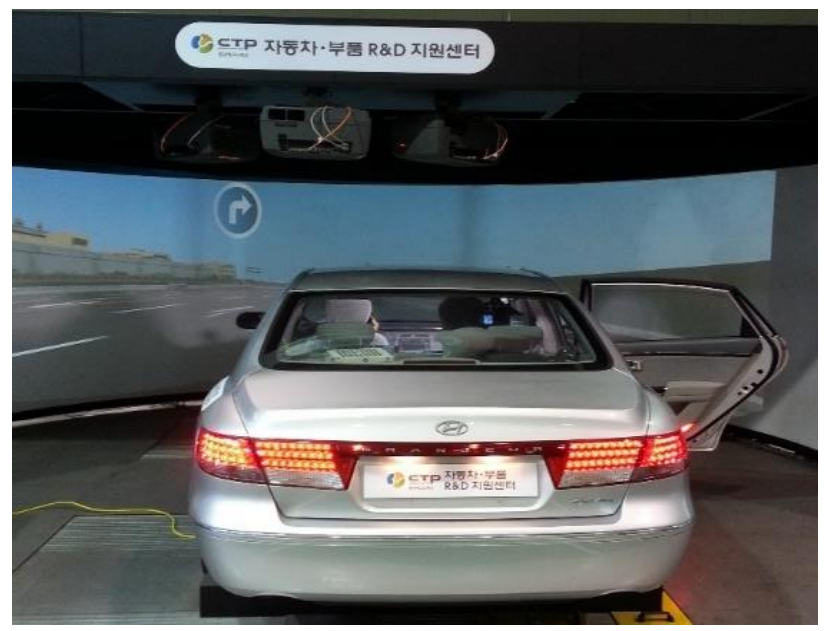

Fig. 1: Driving Simulator.

The participants BAC levels were tested with a blowing-type (Model: CA 2000) digital alcohol detector (Accuracy: $\pm 0.01 \%$ at $0.10 \%$ BAC) (Figure. 2). Three BAC level measurements were taken from the participants for each testing, and the average was used to reduce measurement errors.

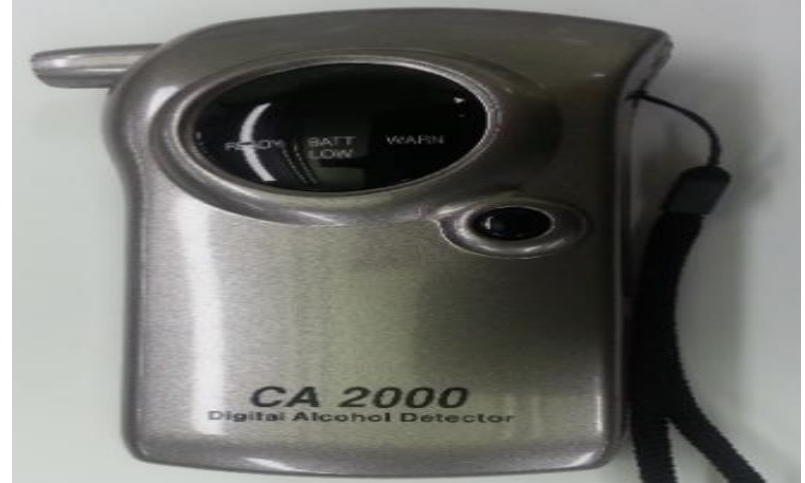

Fig. 2: Digital Alcohol Detector (Model: Ca 2000).

c) Physiological Responses

An EEG and ECG test was conducted to study the response of central and autonomic nervous system. The specified physiological data were measured with Biopac MP 150 system and analyzed with AcqKnowledge (ver. 4.2) software. The sampling frequency was set at $1000 \mathrm{~Hz}$. By the 10-20 international system, the EEG electrodes were attached to the frontal lobe $(\mathrm{Fz})$ and occipital lobe $(\mathrm{Oz})$, and also, a reference electrode was attached to the left earlobe. The ECG was measured using bipolar leads. The raw EEG signals were digitized and low-pass filtered, and then frequency analysis was done using FFT transform. From EEG analysis, the parameters alpha power frequency and theta power frequency were estimated. From ECG analysis, the heart rate was determined. d) Driving Performances

The driving performance measured were accident rate/crash rate and over speed rate. The accident rate refers to the number of accidents per driver. The over speed rate refers to the number of time the participants drove the vehicle above the specified speed limit.

e) Experimental Design and Procedures

The participants needed to conduct experiments at four BAC level $(0.00,0.03 .0 .05$, and $0.1 \%)$. Every participant took part the simulated driving experiment for four times with $30 \mathrm{~min}$ interval. A highway scenario was used, where participants were instructed to drive at the speed of $50,70,90,110 \mathrm{~km} / \mathrm{h}$ for one minute each in a driving simulator. The scenario considered was 5 min driving on a highway with different speed limits, crossings, and unexpected event. Before the first experimental session, a 10-min practice was allowed for each participant. Ample rest time was given to practising and a real test. For baseline condition, i.e., BAC level $0.00 \%$, participants completed the first session. After the first experimental session, participants were asked to drink the Korean liquor soju ( $20 \%$ of alcohol content) about $50 \mathrm{ml}$ (1 shot). About 20 minutes after consumption of alcohol, participants BAC level was measured using digital alcohol detected every 2 minutes. When the participants reached the target BAC levels, the simulated driving commenced. If target BAC level not achieved we encouraged the subjects to drink more. If the participant's BAC level above the target BAC level, the participants not allowed to continue the experiment. Similar procedure repeated for other experimental condition.

f) Statistical Analysis

Analyses of variance (ANOVA) with a repeated measures design was used to investigate the effects of the independent variable (BAC level) on each of the dependent variable. The BAC level considered were $0.00,0.03,0.05$, and $0.1 \%$. The dependent variables were accident rate, over speed rate, alpha power frequency, theta power frequency, and heart rate. Multiple comparisons were performed using post hoc (LSD) test. Statistical analyzes were performed using SPSS (release 18, SPSS Inc., Chicago). The confidence level for statistical significance was set at 95\% (alpha $=$ $0.05)$. 


\section{Results}

1) Driving Performances

a) Accident Rate

The accident rate was estimated depending on the BAC level (\%) (Figure $3 \&$ Table 2). A repeated measures ANOVA with a sphericity correction determined that mean accident rate differ statistically significantly between BAC levels $(\%)(\mathrm{F}(3,21)=17.853, \mathrm{p}$ $<0.05)$. Post hoc tests using LSD correction revealed that BAC level $(\%)$ caused a statistically significant increase in accident rate (Table 3). Therefore, the result concludes that an increased BAC level $(\%)$ produced a statistically significant increase in accident rate.

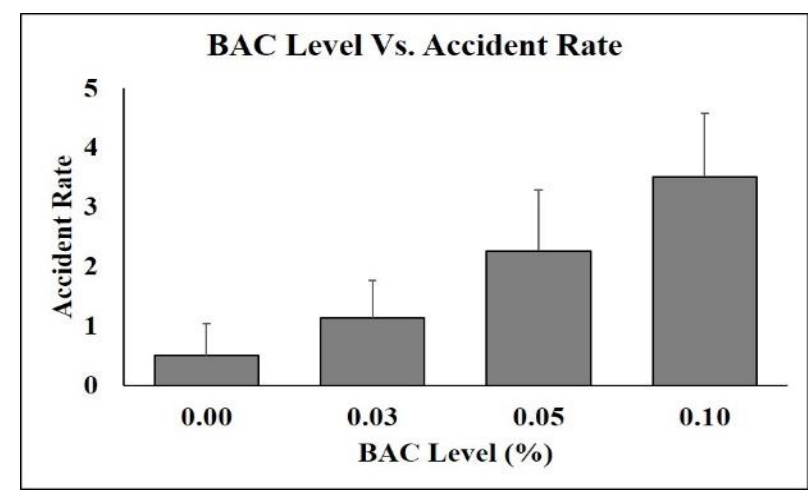

Fig. 3: Accident Rate Based on BAC Level (\%).

b) Over Speed Rate.

The over speed rate was estimated depending on the BAC level (\%) (Figure $4 \&$ Table 2). A repeated measures ANOVA with a sphericity correction determined that mean over speed rate differed statistically significantly between BAC levels $(\%)(\mathrm{F}(3,21)$ $=73.674, \mathrm{p}<0.05)$. Post hoc tests using LSD correction revealed that BAC level $(\%)$ caused a statistically significant increase in over speed rate (Table 3 ). Therefore, the result concludes that an increased BAC level (\%) triggered a statistically significant increase in over speed rate.

Table 2: Descriptive Statistics of Driving Performance Based on BAC Level $(\%)$

\begin{tabular}{lll}
\hline $\begin{array}{l}\text { BAC Level } \\
(\%)\end{array}$ & Accident rate $(\operatorname{Avg} \pm$ & $\begin{array}{l}\text { Over speed rate }(\text { Avg } \pm \\
\text { SD) }\end{array}$ \\
\hline 0.00 & $0.50 \pm 0.54$ & $2.25 \pm 1.49$ \\
0.03 & $1.13 \pm 0.64$ & $4.50 \pm 1.77$ \\
0.05 & $2.25 \pm 1.04$ & $14.13 \pm 3.80$ \\
0.1 & $3.50 \pm 1.07$ & $19.38 \pm 2.62$ \\
\hline
\end{tabular}

Table 3: Post-Hoc Test Result Comparing Accident Rate and Over Speed Rate Based on BAC Level $(\%)$

\begin{tabular}{llll}
\hline $\begin{array}{l}\text { BAC Level } \\
(\%)\end{array}$ & $\begin{array}{l}\text { BAC Level } \\
(\%)\end{array}$ & $\begin{array}{l}\text { Accident rate }(\mathrm{p}- \\
\text { value })\end{array}$ & $\begin{array}{l}\text { Over speed rate }(\mathrm{p}- \\
\text { value })\end{array}$ \\
\hline & 0.03 & .095 & $.007^{*}$ \\
0.00 & 0.05 & $.004^{*}$ & $.000^{*}$ \\
& 0.1 & $.000^{*}$ & $.000^{*}$ \\
0.03 & 0.05 & $.038^{*}$ & $.001^{*}$ \\
0.05 & 0.1 & $.001^{*}$ & $.000^{*}$ \\
$* \mathrm{p}<0.05$. & 0.1 & .060 & $.004^{*}$ \\
\hline
\end{tabular}

$* \mathrm{p}<0.05$.

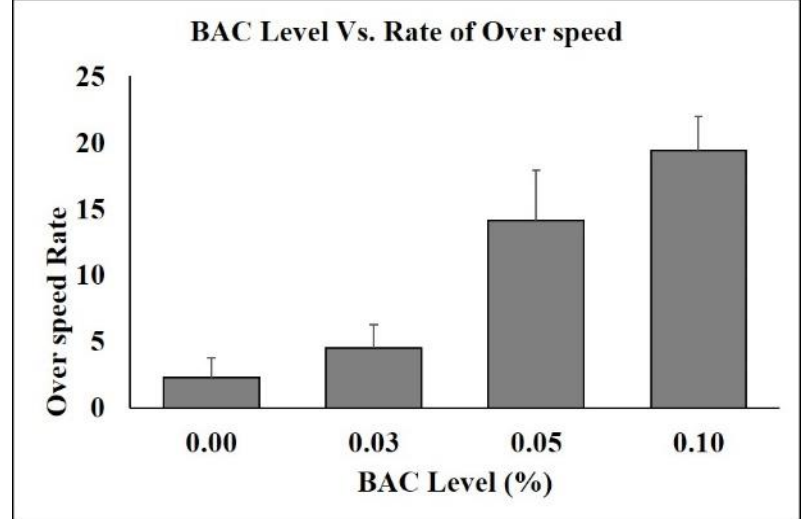

Fig. 4: Over Speed Rate Based on BAC Level (\%).

2) Physiological Responses

The sample (Fig. 5) power of alpha, beta, and theta waveforms are given by comparing normal and alcoholic (at BAC $=0.03 \%$ ). Decreased power of alpha wave observed for alcoholic compared to normal. However, the increased power of beta and theta wave were observed for an alcoholic [4]. The descriptive statistics of physiological responses based on BAC level (\%) shown in Table 4 a) EEG - Frontal - Alpha Power

The frontal lobe alpha power frequency was estimated depending on the BAC level (\%) (Figure $6 \&$ Table 4). A repeated measures ANOVA with a sphericity correction determined that average of alpha power frequency at frontal lobe differ statistically significantly between BAC levels $(\%)(\mathrm{F}(3,21)=58.322, \mathrm{p}<0.05)$. Post hoc tests using LSD correction revealed that BAC level (\%) caused a statistically significant decrease in alpha power frequency at frontal lobe (Table 3). Therefore, the result concludes that an increased BAC level (\%) caused a statistically significant decrease in alpha power frequency at the frontal lobe.

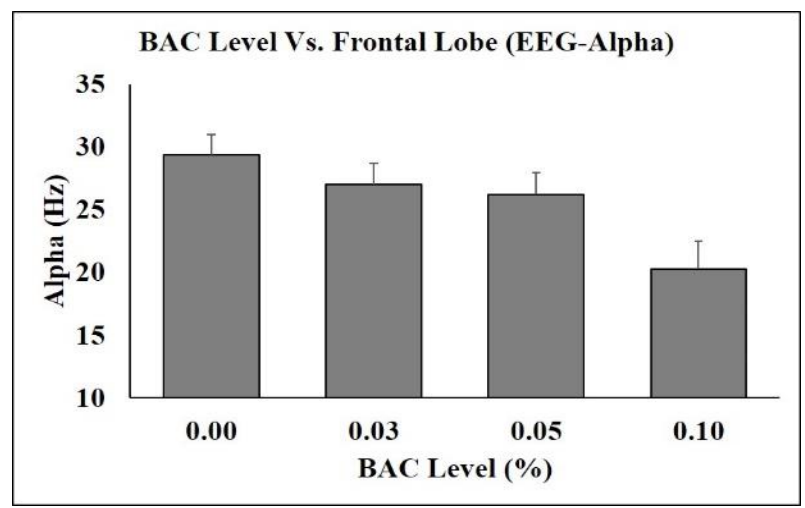

Fig. 5: Frontal Lobe Alpha Power Frequency Based on BAC Level (\%)

b) EEG - Occipital - Alpha Power

The occipital lobe alpha power frequency was estimated depending on the BAC level (\%) (Figure $7 \&$ Table 4). A repeated measures ANOVA with a sphericity correction determined that average of alpha power frequency at occipital lobe differ statistically significantly between BAC levels (\%) $(\mathrm{F}(3,21)=103.938, \mathrm{p}<0.05$. Post hoc tests using LSD correction revealed that BAC level $(\%)$ caused a statistically significant decrease in alpha power frequency at occipital lobe (Table 3). Therefore, the result concludes that an increased BAC level $(\%)$ caused a statistically significant decrease in alpha power frequency at the occipital lobe. 


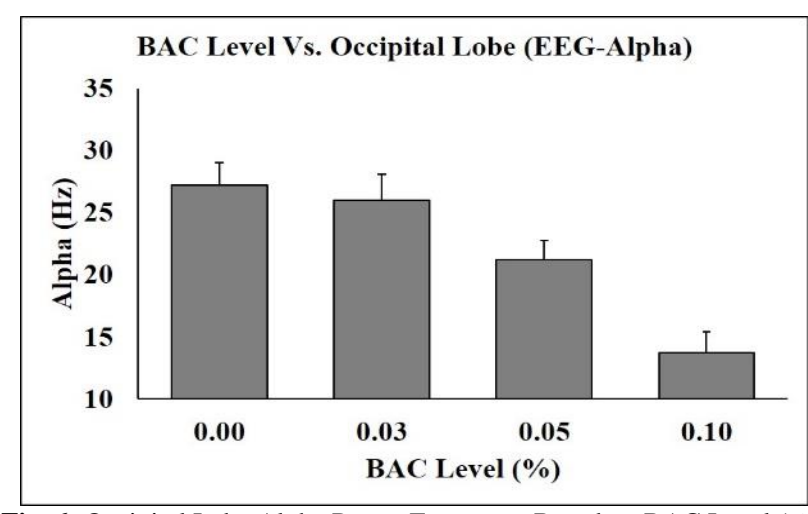

Fig. 6: Occipital Lobe Alpha Power Frequency Based on BAC Level (\%)
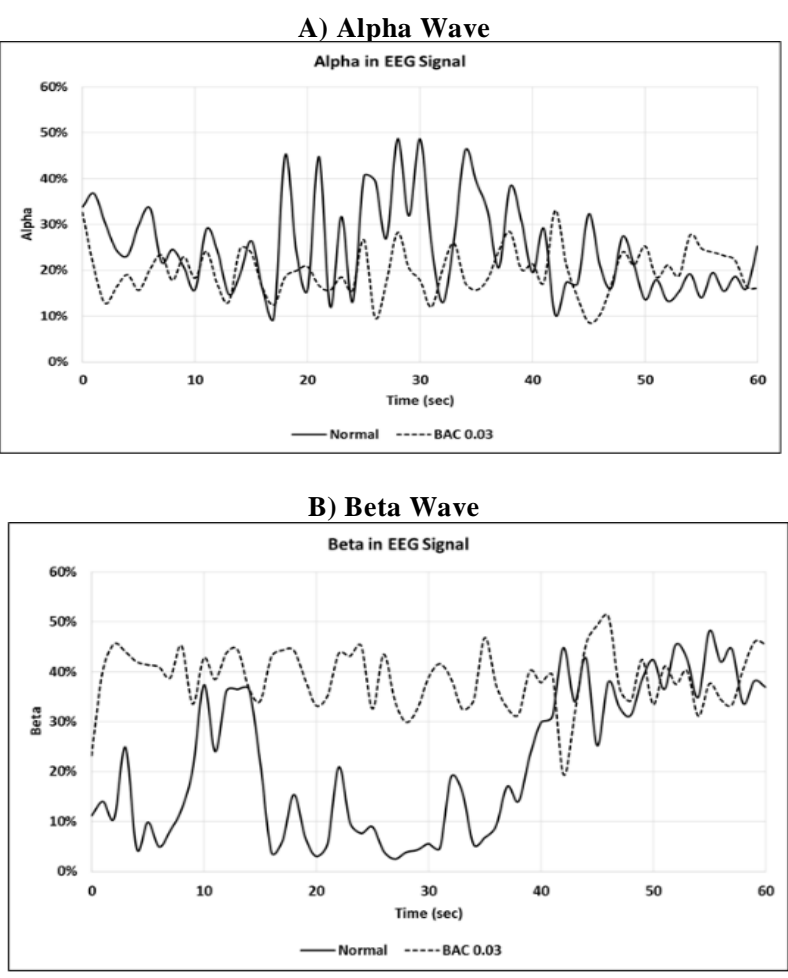

C) Theta Wave

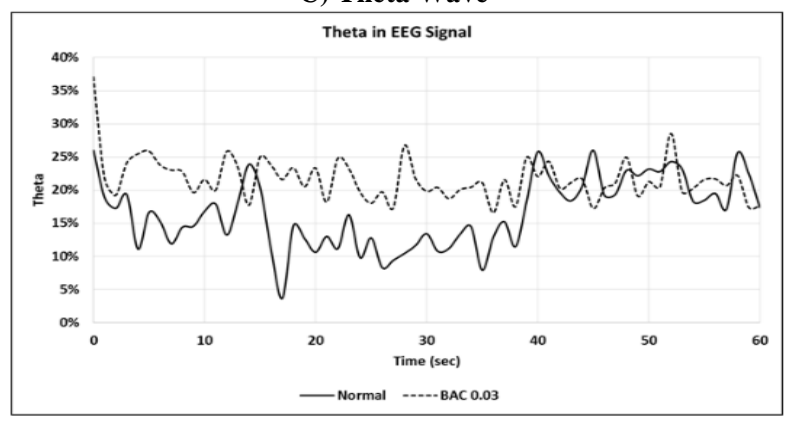

Fig. 7: Sample EEG Waveform Comparing Alcoholic $(\mathrm{BAC}=0.03 \%)$ and Normal.

Table 4: Descriptive Statistics of Physiological Responses Based on BAC Level (\%)

\begin{tabular}{llllll}
$\begin{array}{l}\text { BAC } \\
\text { Level } \\
(\%)\end{array}$ & $\begin{array}{l}\text { Alpha } \\
\text { Frontal } \\
\text { (Avg } \pm\end{array}$ & $\begin{array}{l}\text { Occipital } \\
\text { (Avg } \pm\end{array}$ & $\begin{array}{l}\text { Theta } \\
\text { Frontal } \\
\text { (Avg } \pm\end{array}$ & $\begin{array}{l}\text { Occipital } \\
\text { (Avg } \pm\end{array}$ & $\begin{array}{l}\text { ECG } \\
\text { Heart rate } \\
\text { (Avg } \pm\end{array}$ \\
\hline \multirow{2}{*}{0.00} & $29.35 \pm$ & $27.18 \pm$ & $12.83 \pm$ & $17.63 \pm$ & $74.43 \pm$ \\
& 1.64 & 1.88 & 2.22 & 1.25 & 5.13 \\
0.03 & $27.02 \pm$ & $25.99 \pm$ & $17.71 \pm$ & $19.10 \pm$ & $84.36 \pm$ \\
& 1.69 & 2.08 & 1.69 & 1.15 & 7.58 \\
0.05 & $26.22 \pm$ & $21.17 \pm$ & $19.41 \pm$ & $24.32 \pm$ & $89.88 \pm$ \\
& 1.74 & 1.59 & 1.81 & 1.14 & 8.67 \\
0.1 & $20.27 \pm$ & $13.74 \pm$ & $28.10 \pm$ & $28.93 \pm$ & $124.24 \pm$ \\
& 2.24 & 1.64 & 2.99 & 2.08 & 15.92 \\
\hline
\end{tabular}

Table 5: Post-Hoc Test Result Comparing Accident Rate and Over Speed Rate Based on BAC Level (\%)

\begin{tabular}{|c|c|c|c|c|c|c|}
\hline \multirow{2}{*}{$\begin{array}{l}\text { BAC } \\
\text { Level } \\
(\%) \\
\end{array}$} & \multirow{2}{*}{$\begin{array}{l}\text { BAC } \\
\text { Level } \\
(\%) \\
\end{array}$} & \multicolumn{2}{|c|}{ EEG - Alpha } & \multicolumn{2}{|c|}{ EEG - Theta } & \multirow[b]{2}{*}{$\begin{array}{l}\text { Heart } \\
\text { Rate }\end{array}$} \\
\hline & & Frontal & Occipital & Frontal & Occipital & \\
\hline \multirow{3}{*}{0.00} & 0.03 & $.001 *$ & .349 & $.000 *$ & $.009 *$ & $.000 *$ \\
\hline & 0.05 & $.000 *$ & $.000 *$ & $.000 *$ & $.000 *$ & $.000 *$ \\
\hline & 0.1 & $.000^{*}$ & $.000 *$ & $.000 *$ & $.000 *$ & $.000 *$ \\
\hline \multirow{2}{*}{0.03} & 0.05 & $.008 *$ & $.001 *$ & $.000 *$ & $.000 *$ & .081 \\
\hline & 0.1 & $.000 *$ & $.000 *$ & $.000 *$ & $.000 *$ & $.000 *$ \\
\hline 0.05 & 0.1 & $.001 *$ & $.000 *$ & $.000 *$ & $.000 *$ & $.000 *$ \\
\hline
\end{tabular}

c) EEG - Frontal - Theta Power

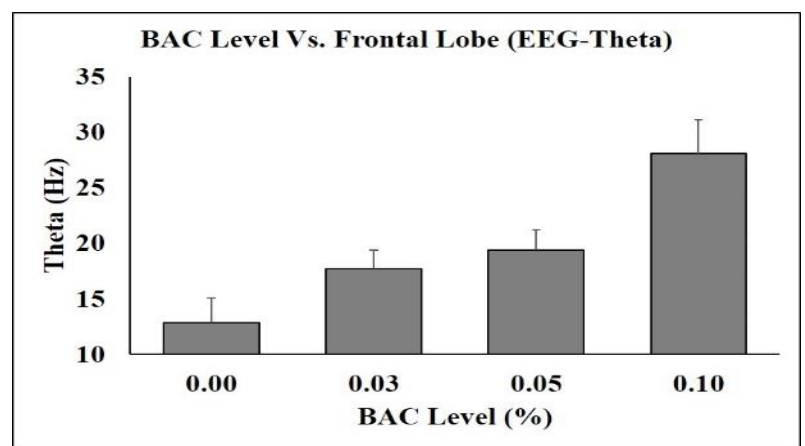

Fig. 8: Frontal Lobe Theta Power Frequency Based on BAC Level (\%)

The frontal lobe theta power frequency was estimated depending on the BAC level (\%) (Figure $8 \&$ Table 4). A repeated measures ANOVA with a sphericity correction determined that average of theta power frequency at frontal lobe differ statistically significantly between BAC levels $(\%)(\mathrm{F}(3,21)=127.766, \mathrm{p}<0.05)$. Post hoc tests using LSD correction revealed that BAC level (\%) caused a statistically significant increase in theta power frequency at frontal lobe (Table 3). Therefore, the result concludes that an increased BAC level (\%) caused a statistically significant increase in theta power frequency at the frontal lobe.

d) EEG - Occipital - Theta Power

The occipital lobe theta power frequency was estimated depending on the BAC level (\%) (Figure $9 \&$ Table 4). A repeated measures ANOVA with a sphericity correction determined that average of theta power frequency at occipital lobe differ statistically significantly between BAC levels $(\%)(\mathrm{F}(3,21)=178.436, \mathrm{p}<0.05)$. Post hoc tests using LSD correction revealed that BAC level (\%) caused a statistically significant increase in theta power frequency at occipital lobe (Table 3). Therefore, the result concludes that an increased BAC level (\%) caused a statistically significant increase in theta power frequency at the occipital lobe.

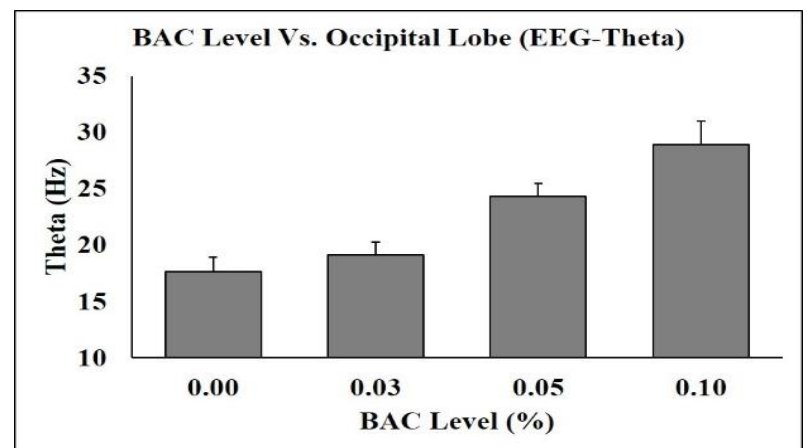

Fig. 9: Occipital Lobe Theta Power Frequency Based on BAC Level (\%).

e) ECG - Heart Rate

The heart rate was estimated depending on the BAC level (\%) (Figure $10 \&$ Table 4). A repeated measures ANOVA with a sphericity correction determined that average of heart rate differ statistically significantly between BAC levels $(\%)(\mathrm{F}(3,21)=106.498$, $\mathrm{p}<0.05)$. Post hoc tests using LSD correction revealed that BAC level $(\%)$ caused a statistically significant increase in heart rate 
(Table 3). Therefore, the result concludes that an increased BAC level (\%) caused a statistically significant increase in heart rate.

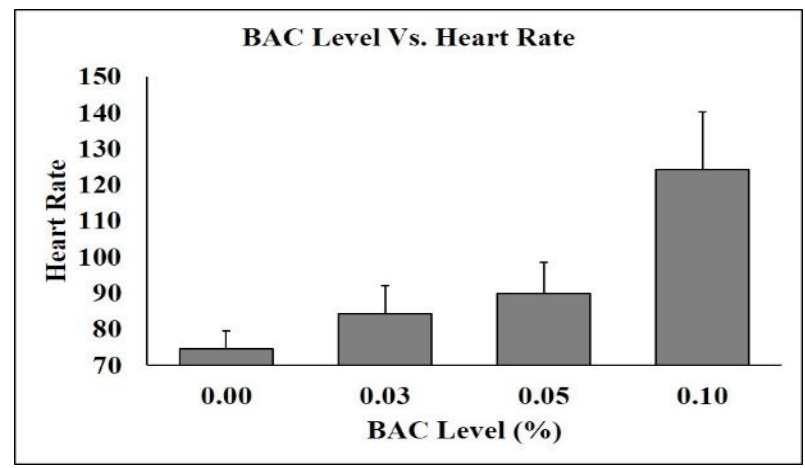

Fig. 10: Heart Rate Based on BAC Level (\%).

\section{Discussion}

The primary importance of this research is improving the understanding of the physiological behavior, especially, neuronal activity of the driver's brain and heart rate while drunk. For that purpose, this study examined the effects of alcohol consumption on driver's physiological behavior and driving performance under the simulated driving environment.

First, accident rate and over speed rate were analyzed to determine the effects of BAC level. The accident rate was significantly increased with BAC level. Also, the over speed rate was significantly increased with BAC level. Zhao et al. [1] stated that the incidence of traffic accident increased with the BAC level. Also reported that driving under the influence of alcohol exhibited the characteristics of adventurous, and moving faster. Based on road traffic accident in Korea [5], the proportion of drunken driving traffic accidents were increased from $22.7 \%$ (BAC level: $0.05-0.09 \%)$ to $38.2 \%(0.10-0.14 \%)$. In this study, the rate of drunken driving traffic accidents was increased from 1.13 times (BAC level: $0.03 \%$ ) to 2.25 times (BAC level: $0.05 \%$ ) to 3.5 times (BAC level: $0.1 \%$ ). The rate of over speed was increased from 4.5 times (BAC level: $0.03 \%$ ) to 14.13 times (BAC level: $0.05 \%$ ) to 19.38 times (BAC level: $0.1 \%$ ). These results conclude that even low dose (BAC level: $0.03 \%$ ) of alcohol consumption significantly $(\mathrm{p}<0.05)$ affects driving performance.

Second, physiological responses were analyzed to determine the effects of BAC level. The frontal lobe alpha power and occipital lobe alpha power frequency were decreased significantly $(\mathrm{p}<$ 0.05) with increased BAC level. In the frontal lobe, the alpha power frequency was reduced $7.92 \%$ (BAC level: 0.03\%) with control, $2.97 \%$ (BAC level: $0.05 \%$ ) with BAC level: $0.03 \%$, and $22.69 \%$ (BAC level: $0.1 \%$ ) with BAC level: $0.05 \%$. The reduced alpha power frequency in the frontal lobe affected the decisionmaking ability. In the occipital lobe, the alpha power frequency was reduced $4.34 \%$ (BAC level: $0.03 \%$ ) with control, $18.57 \%$ (BAC level: $0.05 \%$ ) with BAC level: $0.03 \%$, and $35.12 \%$ (BAC level: $0.1 \%$ ) with BAC level: $0.05 \%$. The reduced alpha power frequency in the occipital lobe affected the vision and integrating visual information ability. Barzelay [32] expressed that alcohol disturbs the ability to reason and to make a decision, which causes longer responses time to road hazards while driving. Mitchell [33] highlighted that alcohol and drug use might affect drivers cognitive functioning, especially decision-making abilities, reasoning, concentration, vision, and ability to follow objects with eyes. NIAAA [34] indicated that even low dose of alcohol consumption (BAC level: $0.03 \%$ ) interfere with voluntary eye movements and weaken the eye's ability to focus and track. Also, the muscle that controls the shape of the eye's lens is affected by alcohol consumption, which causes the ability to focus on a driver [35].

Also, alcohol would negatively affect driver's ability on the judgment of succeeding distance and depth perception $[1,26]$. The frontal lobe theta power and occipital lobe theta power frequency were increased significantly $(\mathrm{p}<0.05)$ with increased BAC level.
In the frontal lobe, the theta power frequency was increased $38.09 \%$ (BAC level: $0.03 \%$ ) with control, $9.60 \%$ (BAC level: $0.05 \%$ ) with BAC level: $0.03 \%$, and $44.77 \%$ (BAC level: $0.1 \%$ ) with BAC level: $0.05 \%$. In the occipital lobe, the theta power frequency was increased $8.36 \%$ (BAC level: $0.03 \%$ ) with control, $27.32 \%$ (BAC level: $0.05 \%$ ) with BAC level: $0.03 \%$, and $18.97 \%$ (BAC level: $0.1 \%$ ) with BAC level: $0.05 \%$. The increased theta power frequency in both frontal and occipital areas enhance the drowsiness [36]. As mentioned earlier, alcoholism can affect the brain and its neuronal activity, specifically, alpha activity decreases and theta activity increases $[11,27]$.

Third, an electrocardiogram was analyzed to determine the effects of BAC level. The heart rate was increased significantly $(\mathrm{p}<0.05)$ with $\mathrm{BAC}$ level. The heart rate was increased $13.34 \%$ (BAC level: $0.03 \%$ ) with control, $6.55 \%$ (BAC level: $0.05 \%$ ) with BAC level: $0.03 \%$, and $38.23 \%$ (BAC level: $0.1 \%$ ) with BAC level: $0.05 \%$. Ryan \& Howes [31] studied the relations between alcohol consumption and heart rate in men and concluded that heart rate increases and R-peak to R-peak interval (RRI) decreases when alcohol intoxication.

The limitation of the present study should also be mentioned. The present study considered only eight subjects, in future, a significant study group must be used although statistical tests were showing strong significant levels with the adequate power which was verified by the direct assessment of power. Also, the present study only measured brain activity from frontal and occipital lobe. However, other parts of the brain and its function could be affected by the effects of alcohol. For example, Ridderinkhof et al. [37] reported that intake of alcohol in moderate doses affects mediofrontal brain function may effect compromised performance. Paulchamy \& Vennila [4] proposed threshold values of alpha, beta, and theta waves to differentiate EEG between alcoholic and nonalcoholic. They have considered the central region of the brain along with frontal and occipital region. Future work would study the effects of alcohol on other brain parts and its function. Therefore, the results presented in this study must be interpreted in the context of the experimental design.

\section{Conclusion}

There have been many studies about the alcohol weakening and driving performance at diverse BAC levels. Moreover, not many studies on driver's physiological behavior at various BAC levels. This study evaluated driver's physiological behavior at different $\mathrm{BAC}$ levels, also, driving performance measures also performed. Both physiological behavior and driving performance confirm that even low dose of alcohol consumption (BAC level: $0.03 \%$ ) would affect driver decision-making ability, vision and integrate visual information ability.

\section{Acknowledgments}

This work was supported by the National Research Council of Science \& Technology (NST) grant by the Korea government (MSIP) (No. CRC-15-05-ETRI).

\section{References}

[1] Zhao, X., Zhang, X., \& Rong, J. 2014. Study of the Effects of Alcohol on Drivers and Driving Performance on Straight Road. Mathematical Problems in Engineering. 1-9. https://doi.org/10.1155/2014/607652.

[2] Keall, M. D., Frith, W. J., \& Patterson, T. L. 2004. The influence of alcohol, age and number of passengers on the nighttime risk of driver fatal injury in New Zealand. Accident Analysis \& Prevention. 36(1): 49-61. https://doi.org/10.1016/S0001-4575(02)00114-8.

[3] Arnedt, J. T., Wilde, G. J., Munt, P. W., \& Maclean, A. W. 2000. Simulated driving performance following prolonged wakefulness and alcohol consumption: separate and combined contributions to impairment. Journal of Sleep Research, 9(3): 233-241. https://doi.org/10.1046/j.1365-2869.2000.00216.x. 
[4] Paulchamy, B., \& Vennila, I. 2012. A proficient system for preventing and acknowledging about the drunken drive by analyzing the neuronal - activity of the brain. ARPN Journal of Engineering and Applied Sciences, 7(8): 1029-1036.

[5] Road traffic accidents in Korea. 2012. Korea Road Traffic Authority (KoROAD), 1-98.

[6] National Highway Traffic Safety Administration (NHTSA). 2010 Assessing the feasibility of vehicle-based sensors to detect alcohol impairment. Tech. Rep. DOT HS, 811 358, US Department of Transportation, Washington, DC, USA.

[7] Li, Y D. Xie, G. Nie, and J. Zhang. 2012. The drink driving situation in China. Traffic Injury Prevention, 13(2): 101-108, 2012. https://doi.org/10.1080/15389588.2011.637097.

[8] Adams, A. J., Brown, B., Haegerstrom-Portnoy, G., Flom, M. C., \& Jones, R. T. 1978. Marijuana, alcohol, and combined drug effects on the time course of glare recovery. Psychopharmacology, 56(1): 81-86. https://doi.org/10.1007/BF00571413.

[9] Williamson, A. M., Feyer, A. M., Mattick, R. P., Friswell, R. \& Finlay-Brown, S. 2001. Developing measures of fatigue using an alcohol comparison to validate the effects of fatigue on performance. Accident Analysis and Prevention. 33(3): 313-326. https://doi.org/10.1016/S0001-4575(00)00045-2.

[10] Zhang, X. L., Begleiter, H., Porjesz, B., \& Litke, A. 1997. Electrophysiological evidence of memory impairment in alcoholic patients. Biological Psychiatry. 42 (12): https://doi.org/10.1016/S0006-3223(96)00552-5.

[11] Chamberlain, E., \& Solomon, R. 2002. The case for a $0.05 \%$ criminal law blood alcohol concentration limit for driving. Injury Prevention, 8(Suppl 3), iii. https://doi.org/10.1136/ip.8.suppl_3.iii1.

[12] Laberg, J. C., \& Löberg, T. 1989. Expectancy and tolerance: a study of acute alcohol intoxication using the balanced placebo design. Journal of studies on alcohol. 50(5): 448-455. https://doi.org/10.15288/jsa.1989.50.448.

[13] Smiley, A. M.1986. Marijuana: On-road and driving simulator studies. Alcohol, Drugs and Driving. 2 (3-4): 121-134.

[14] Harrison, E. L., Marczinski, C. A., \& Fillmore, M. T. 2007. Driver training conditions affect sensitivity to the impairing effects of alcohol on a simulated driving test to the impairing effects of alcohol on a simulated driving test. Experimental and clinical psychopharmacology: 15(6): 588. https://doi.org/10.1037/1064-1297.15.6.588.

[15] Harrison, E. L., \& Fillmore, M. T. 2005. Are bad drivers more impaired by alcohol? Sober driving precision predicts impairment from alcohol in a simulated driving task. Accident Analysis \& Prevention. 37(5): 882-889. https://doi.org/10.1016/j.aap.2005.04.005.

[16] Fillmore, M. T., Blackburn, J. S., \& Harrison, E. L. 2008. Acute disinhibiting effects of alcohol as a factor in risky driving behavior. Drug and alcohol dependence, 95(1): 97-106. https://doi.org/10.1016/j.drugalcdep.2007.12.018.

[17] Moon, M. K., Subramaniyam, M., \& Park, S. J. 2013. Older Drivers' Physiological Responses during Last-Minute Braking in a Driving Simulator (No. 2013-01-1245). SAE Technical Paper.

[18] Mun, K. R., Choi, J. S., Kang, D. W., Bang, Y. H., ... \& Tack, G. R. 2010. The effects of secondary task on driving performance - control of vehicle and analysis of motion signal. Korean Journal of the Science and Emotion and Sensibility. 13(4): 613-620.

[19] Kim, S. H., Choi, J.S., Kang, D.W., Oh, H. S. \& Tack, G.R. 2011 The effects of driving performance during driving with sending text message and searching navigation: a study among 50s taxi drivers. Korean Journal of the Science and Emotion and Sensibility. 14(4): 571-580.

[20] Lal, S. K., \& Craig, A. 2002. Driver fatigue: electroencephalography and psychological assessment. Psychophysiology. 39(3): 313-321. https://doi.org/10.1017/S0048577201393095.

[21] Park, S. J., Min, S. N., Lee, H., \& Subramaniyam, M. 2015. A driving simulator study: elderly and younger drivers physiological, visual and driving behavior on intersection. Proceedings 19th Triennial Congress of the IEA, Melbourne, Australia.

[22] Park, S. J., Subramaniyam, M., Moon, M. K., \& Kim, D. G. 2013. Physiological evaluation of older drivers emotional states while driving with and without navigation in a driving simulator. SAE World Congress \& Exhibition, Detroit, USA.

[23] Subramaniyam, M., Kim, S. E., Park, S. J., Lee, H., \& Min, S. N. 2015. Alcohol Intoxication Effects on Simulated Driving. International Conference on Emotion and Sensibility (ICES 2015), Jeju, Korea.

[24] Subramaniyam, M., Min, S. N., Lee, H., \& Park, S. J. 2014. Physiological responses of aging to sudden braking situation in a driving simulator. Korea Society of Physiological and Anthropological Science (KSPA) conference, Daejeon, Korea.
[25] Ronen, A., Moed, Y., Gertner, R., Oron-Gilad, T., Cassuto, Y., \& Shinar, D. 2004. Subjective feeling, performance and physiological strain while driving under alcohol intoxication. In Proceedings of the 17th International Conference on Alcohol, Drugs and Traffic Safety, Glasgow, UK. Institute for Human Psychopharmacology, University of Limburg.

[26] Nikulin, V. V., Nikulina, A. V., Yamashita, H., Rossi, E. M., \& Kähkönen, S. 2005. Effects of alcohol on spontaneous neuronal oscillations: a combined magnetoencephalography and electroencephalography study. Progress in Neuro-Psychopharmacology and Biological Psychiatry. 29(5): 687-693. https://doi.org/10.1016/j.pnpbp.2005.04.014.

[27] Malar, E., Gauthaam, M., \& Chakravarthy, D. 2011. A Novel Approch for the Detection of Druken Driving using the Power Spectral Density Analysis of EEG. International Journal of Computer Applications: 21(7):10-14. https://doi.org/10.5120/2525-3436.

[28] Healey, J. A. 2000. Wearable and automotive systems for affect recognition from physiology. Doctoral dissertation, Massachusetts Institute of Technology.

[29] Lee, J. 2010. A study on the estimation possibility of driver's stress degrees with the HRV analysis. Korean Journal of the Science and Emotion and Sensibility. 13(1): 61-68.

[30] Ryan, J. M., \& Howes, L. G. 2002. Relations between alcohol consumption, heart rate, and heart rate variability in men. Heart. 88(6): 641-642. https://doi.org/10.1136/heart.88.6.641.

[31] Barzelay, M.E. 1986. Scientific automobile accident reconstruction, vol 1. NewYork: Matthew Bender.

[32] Mitchel, M. C. 1985. Alcohol-induced impairment of central nervous system function: behavioural skills involved in driving. Journal of Studies on Alcohol. Supplement 10, 109-116. https://doi.org/10.15288/jsas.1985.s10.109.

[33] National Institute on Alcohol Abuse and Alcoholism. 1994 Alcohol-related impairment. Alcohol Alert. 25 (1)

[34] Moskowitz, H., Fiorentino, D. 2000. A review of the literature on the effects of low doses of alcohol on driving-related skills. Washington, DC: Natinal Highway Traffic Safety Administration.

[35] Hoffmann, E., Keppel-Hesselink, J. M., \& da Silveira Barbosa, Y. M. 2001. Effects of a psychedelic, tropical tea, ayahuasca, on the electroencephalographic (EEG) activity of the human brain during a shamanistic ritual. MAPS Spring, 25-30.

[36] Ridderinkhof, R. K., Vlugt, Y. D., Bramlage, A., Spaan, M., Elton, M., Snel, J., \& Band, P. H. 2002. Alcohol Consumption Impairs Detection of Performance Errors in Mediofrontal Cortex. Science. 298 (5601): 2209-2211. https://doi.org/10.1126/science.1076929.

[37] Nash, H. 1962. Alcohol and Caffeine: A study of their physiological effects, Charles C. Thomas, Springfield, Ill, USA. https://doi.org/10.1037/14179-000.

[38] T. Padmapriya and V. Saminadan, "Improving Throughput for Downlink Multi user MIMO-LTE Advanced Networks using SINR approximation and Hierarchical CSI feedback", International Journal of Mobile Design Network and Innovation- Inderscience Publisher, ISSN : 1744-2850 vol. 6, no.1, pp. 14-23, May 2015.

[39] S. V. Manikanthan and K.srividhya "An Android based secure access control using ARM and cloud computing", Published in: Electronics and Communication Systems (ICECS), 2015 2nd International Conference on 26-27 Feb. 2015,Publisher: IEEE, https://doi.org/10.1109/ECS.2015.7124833. 